\title{
Impact of body mass index on surgical outcomes of gastric cancer
}

\author{
Fan Feng ${ }^{1 \dagger}$, Gaozan Zheng ${ }^{1 \dagger}$, Xiaohua Guo ${ }^{1 \dagger}$, Zhen Liu', Guanghui Xu', Fei Wang ${ }^{1,2}$, Qiao Wang ${ }^{1,3}$, Man Guo ${ }^{1}$, \\ Xiao Lian ${ }^{1}$ and Hongwei Zhang ${ }^{1 *}$
}

\begin{abstract}
Background: The association between body mass index (BMI) and clinical outcomes of gastric cancer were still under debate. The aim of the present study was to investigate the impact of BMI on intraoperative conditions, postoperative complications and prognosis of gastric cancer.
\end{abstract}

Methods: From October 2008 to March 2015, 1210 gastric cancer patients treated with D2 gastrectomy were enrolled in the present study. Patients were divided into three groups: low BMl group (BMl $<18.5 \mathrm{Kg} / \mathrm{m}^{2}$ ), normal BMl group (18. $5 \mathrm{Kg} / \mathrm{m}^{2} \leq \mathrm{BMl}<25.0 \mathrm{Kg} / \mathrm{m}^{2}$ ) and high BMl group $\left(\mathrm{BMI} \geq 25.0 \mathrm{Kg} / \mathrm{m}^{2}\right)$. Clinicopathological characteristics and prognosis of patients were recorded and analyzed. Propensity score matching was used to match patients in the three groups.

Results: There were 107 patients in low BMl group (8.9\%), 862 patients in normal BMl group (71.2\%) and 241 patients in high BMI group (19.95\%). Before matching, BMI was inversely associated with tumor size, tumor depth, lymph node metastasis (LNM) and tumor stage (all $P<0.05$ ). After matching, the clinicopathological features were all comparable among the three groups (all $P>0.05$ ). High BMl was associated with increased blood loss and operation time, and deceased number of retrieved lymph nodes (all $P<0.05$ ). For postoperative complications, low BMI was associated with decreased rate of postoperative fever $(P=0.025)$. Age, BMl, tumor size, Borrmann type, pathological type, type of gastrectomy, tumor depth, LNM and tumor stage were risk factors for the prognosis of gastric cancer. Multivariate analysis showed that only BMI, tumor size, tumor depth and LNM were independent prognostic factors. The overall survival of patients with low BMI was significantly worse than patients with normal $(P<0.05)$ or high BMI $(P<0.05)$. However, the overall survival was comparable between patients with normal and high BMI $(P>0.05)$.

Conclusions: BMI was inversely associated with tumor size, tumor depth, LNM and tumor stage. High BMI was associated with increased blood loss and operation time, and deceased number of retrieved lymph nodes. Low BMI was associated with decreased rate of postoperative fever and decreased survival.

Keywords: Gastric cancer, Complications, Prognosis, BMI

\section{Background}

Gastric cancer is the fourth most common cancer in the world [1] and the second most common cancer in China [2]. Surgical resection with extended lymph node clearance remains the only curative treatment for gastric cancer. It is often diagnosed at an advanced stage. Thus, the prognosis of gastric cancer is still not promising, even with the rapid advances in surgical techniques and adjuvant therapy [3].

\footnotetext{
* Correspondence: zhanghwfmmu@126.com

${ }^{\dagger}$ Equal contributors

${ }^{1}$ Division of Digestive Surgery, Xijing Hospital of Digestive Diseases, Fourth Military Medical University, 127 West Changle Road, Xi'an, Shaanxi 710032, China

Full list of author information is available at the end of the article
}

Tumor patients always tend to suffer from malnutrition and lose weight because of decreased oral intake and alterations in metabolism [4]. The incidence of malnutrition in tumor patients is reported to be ranged from $10 \%$ to $85 \%$ according to the type, location and stage, etc. [4]. Body mass index (BMI) was an effective measurement for evaluating nutritional status of cancer patients [5]. In recent years, the associations between BMI and clinical outcomes of cancer patients have been widely investigated [6-9], including gastric cancer [10]. Some studies reported that BMI was associated with postoperative complications [4] and prognosis [11] of gastric cancer. However, no association between BMI 
Table 1 Correlation between clinicopathological characteristics and BMI before matching

\begin{tabular}{|c|c|c|c|c|c|c|c|c|}
\hline Characteristics & $\begin{array}{l}\text { Low BMl } \\
(n=107)\end{array}$ & $\begin{array}{l}\text { Normal BMl } \\
(n=862)\end{array}$ & $\begin{array}{l}\text { High BMl } \\
(n=241)\end{array}$ & $P$ value & Characteristics & $\begin{array}{l}\text { Low BMl } \\
(n=107)\end{array}$ & $\begin{array}{l}\text { Normal BMl } \\
(n=862)\end{array}$ & $\begin{array}{l}\text { High BMl } P \text { value } \\
(n=241)\end{array}$ \\
\hline Gender & & & & & $\mathrm{lb}$ & 3 & 50 & 17 \\
\hline Male & 83 & 677 & 189 & 0.974 & Ila & 10 & 100 & 34 \\
\hline Female & 24 & 185 & 52 & & $\| \mathrm{b}$ & 19 & 122 & 45 \\
\hline Age & & & & & Illa & 21 & 109 & 27 \\
\hline$\leq 60$ & 66 & 501 & 134 & 0.558 & Illb & 16 & 163 & 37 \\
\hline$>60$ & 41 & 361 & 107 & & IIIc & 30 & 178 & 34 \\
\hline
\end{tabular}

Tumor location

Upper third

$33 \quad 300 \quad 92$

Middle third

Lower third

Entire

Tumor size (cm)

$$
\leq 5
$$$$
>5
$$

Borrmann type

I
II
II

19
29
37
12

Pathological type

Well differentiated 6

Moderately differentiated 22

Poorly differentiated $\quad 74$

Signet ring cell or Mucinous

Type of gastrectomy

Proximal
Distal
Total

Tumor depth

T1

$\mathrm{T} 2$

$\mathrm{T} 3$

T4a

$T 4 b$

Lymph node metastasis

$\begin{array}{ccccc}\text { N0 } & 23 & 291 & 99 & 0.005 \\ \text { N1 } & 20 & 141 & 49 & \\ \text { N2 } & 20 & 153 & 33 & \\ \text { N3a } & 26 & 182 & 45 & \\ \text { N3b } & 18 & 95 & 15 & \\ \text { Tumor stage } & & & & \\ \text { la } & 8 & 140 & 47 & 0.006\end{array}$

Table 1 Correlation between clinicopathological characteristics and BMI before matching (Continued)

and clinical outcomes of gastric cancer has also been reported $[12,13]$.

Given this situation, the aim of the present study was to investigate the impact of BMI on the clinical outcomes of gastric cancer.

\section{Methods}

This study was performed in the Xijing Hospital of Digestive Diseases affiliated to the Fourth Military Medical University. From October 2008 to March 2015, 1210 gastric cancer patients treated with D2 gastrectomy were enrolled in the present study. All patients were treated with total, proximal or distal D2 gastrectomy. The surgical procedure was based on the recommendations of the Japanese Gastric Cancer Treatment Guidelines [14]. The postoperative chemotherapy was given to patients according to the NCCN guideline for gastric cancer. This study was approved by the Ethics Committee of Xijing Hospital, and written informed consent was obtained from all patients before surgery.

Clinicopathological data including gender, age, BMI, tumor location, tumor size, Borrmann type, pathological type, type of gastrectomy, tumor depth, lymph node metastasis and tumor stage were collected. Surgery-related data including blood loss, operation time, number of retrieved lymph nodes and length of postoperative stay were recoded. Postoperative complications within 30 days including pneumonia, fever, wound disruption, wound infection, abdominal bleeding, anastomosis leakage, chyle leakage, gastric stasis, pleural effusion and ileus were also recorded through telephone and outpatient follow up. The survival of patients was followed up till November 2016 every 3 months.

BMI was calculated as body weight (kilograms) divided by height (meters) squared. Patients were divided into three groups according to BMI level: low BMI group (BMI $\left.<18.5 \mathrm{Kg} / \mathrm{m}^{2}\right)$, normal BMI group $\left(18.5 \mathrm{Kg} / \mathrm{m}^{2} \leq \mathrm{BMI}<\right.$ $\left.25.0 \mathrm{Kg} / \mathrm{m}^{2}\right)$ and high BMI group (BMI $\left.\geq 25.0 \mathrm{Kg} / \mathrm{m}^{2}\right)$.

To reduce bias, propensity score matching was used in our present study. The parameters used for propensity score matching was age, gender, tumor location, tumor 
Table 2 Correlation between clinicopathological characteristics and BMl after matching

\begin{tabular}{|c|c|c|c|c|c|c|c|c|c|}
\hline Characteristics & $\begin{array}{l}\text { Low BMl } \\
(n=104)\end{array}$ & $\begin{array}{l}\text { Normal BMI } \\
(n=416)\end{array}$ & $\begin{array}{l}\text { High BMI } \\
(n=104)\end{array}$ & $P$ value & Characteristics & $\begin{array}{l}\text { Low BMI } \\
(n=104)\end{array}$ & $\begin{array}{l}\text { Normal BMl } \\
(n=416)\end{array}$ & $\begin{array}{l}\text { High BMI } \\
(n=104)\end{array}$ & $P$ value \\
\hline Gender & & & & & $\mathrm{lb}$ & 3 & 24 & 6 & \\
\hline Male & 82 & 331 & 76 & 0.353 & lla & 10 & 39 & 9 & \\
\hline Female & 22 & 85 & 28 & & $\| \mathrm{b}$ & 19 & 59 & 16 & \\
\hline Age & & & & & Illa & 21 & 41 & 12 & \\
\hline$\leq 60$ & 60 & 220 & 62 & 0.379 & $\| l \mid b$ & 16 & 109 & 26 & \\
\hline$>60$ & 44 & 196 & 42 & & IIIc & 27 & 104 & 25 & \\
\hline
\end{tabular}

Tumor location

Upper third

Middle third

Lower third

Entire

Tumor size (cm)

$$
\leq 5
$$$$
>5
$$

Borrmann type

।
II
IV

Pathological type

Well differentiated 6

Moderately differentiated 21

Poorly differentiated

Signet ring cell or Mucinous

Type of gastrectomy

Proximal
Distal
Total

\section{Tumor depth}

T1

$\mathrm{T} 2$

T3

T4a

$T 4 b$

Lymph node metastasis

No
N1
N3a
N3b

Tumor stage

$\begin{array}{lll}19 & 59 & 11 \\ 27 & 110 & 32 \\ 37 & 162 & 42 \\ 11 & 35 & 7\end{array}$

0.329

$\begin{array}{ll}105 & 22 \\ 61 & 19 \\ 87 & 16 \\ 105 & 33 \\ 58 & 14\end{array}$

40
Table 2 Correlation between clinicopathological characteristics and $\mathrm{BMI}$ after matching (Continued)

size, type of resection, pathological type, tumor depth and LNM. (SPSS Inc., Chicago, IL, USA). Discrete variables were analyzed using Chi-square test or Fisher's exact test. Continuous variables were expressed as median (interquartile range) and analyzed using nonparametric test. Significant prognostic risk factors identified by univariate analysis were further assessed by multivariate analysis using the Cox's proportional hazards regression model. Overall survival was analyzed by Kaplan-Meier method. The $P$ value was considered to be statistically significant at $5 \%$ level.

\section{Results}

There were 949 male (78.4\%) and 261 female (21.6\%). The median age was 59 years (20-87). There were 107 patients in the low BMI group (8.9\%), 862 patients in the normal BMI group (71.2\%) and 241 patients in the high BMI group (19.95\%). The median follow-up of the low, normal and high BMI group was 22.4 (1.3-66.2) months, 25.0 (1.4-73.5) months and 25.0 (1.6-74.6) months, respectively. The associations between clinicopathological characteristics and BMI were summarized in Table 1. The results showed that BMI was not associated with age, gender, tumor location, Borrmann type, differentiation status and type of resection (all $P>0.05$ ). However, BMI was inversely associated with tumor size, tumor depth, LNM and tumor stage (all $P<0.05$ ).

To reduce bias, propensity score matching was used to match patients in the three groups. After matching, there were 104 patients in the low BMI group, 416 patients in the normal BMI group and 104 patients in the high BMI group. The clinicopathological features were comparable among the three groups after matching (Table 2, all $P>0.05$ ).

The association between BMI and surgery-related parameters were shown in Table 3. The results showed that patients in the high BMI group was associated with increased blood loss and operation time, and deceased number of retrieved lymph nodes (all $P<0.05$ ). The
Data were processed using SPSS 22.0 for Windows 
Table 3 Comparison of surgery-related parameters after matching

\begin{tabular}{lllll}
\hline Characteristics & Low BMl & Normal BMl & High BMl & $P$ value \\
\hline Blood loss $(\mathrm{ml})$ & $150(100,200)$ & $150(100,200)$ & $200(150,350)$ & $217.5(175,263.75)$ \\
Operation time $(\mathrm{min})$ & $170(140,220)$ & $185(150,230)$ & $23(19,27)$ & $<0.001$ \\
Number of retrieved lymph nodes & $26(22,33)$ & $26(21,32)$ & $8(6,9)$ & $<.001$ \\
Length of postoperative stay & $7(6,9)$ & $7(6,9)$ & 0.001 \\
\hline
\end{tabular}

length of postoperative stay was comparable among the three groups $(P=0.179)$.

The association between BMI and postoperative complications were shown in Table 4. The results showed that patients in the low BMI group was associated with decreased rate of postoperative fever $(P=0.025)$. However, BMI was not associated with other complications (all $P>0.05$ ).

The risk factors for the prognosis of gastric cancer patients were analyzed using univariate analysis and shown in Table 5. The results showed that age, BMI, tumor size, Borrmann type, pathological type, type of gastrectomy, tumor depth, LNM and tumor stage were associated with the prognosis of gastric cancer. Multivariate analysis showed that only BMI, tumor size, tumor depth and LNM were independent prognostic factors (Table 6).

The overall survival of gastric cancer patients stratified by BMI was shown in Fig. 1. The overall survival of patients with low BMI was significantly worse than patients with normal $(P<0.001)$ or high BMI $(P<0.001)$. However, the overall survival was comparable between patients with normal and high BMI $(P=0.150)$. Further, the overall survival of patients stratified by tumor stage were analyzed. For stage I patients, the overall survival was comparable among the three groups $(P=0.753)$. For stage II patients, the overall survival of patients with low BMI was significantly worse than that with normal $(P=0.032)$ or high BMI $(P=0.023)$. The overall survival of patients with normal and high BMI was comparable $(P=0.458)$. For stage III patients, the overall survival of patients with low BMI

Table 4 Comparison of postoperative complications after matching

\begin{tabular}{lllll}
\hline Complications & Low BMl & Normal BMI & High BMI & $P$ value \\
\hline Fever & 8 & 74 & 21 & 0.025 \\
Pneumonia & 6 & 32 & 8 & 0.788 \\
Wound infection & 0 & 1 & 0 & 0.778 \\
Wound disruption & 0 & 4 & 2 & 0.364 \\
Anastomosis leakage & 0 & 9 & 0 & 0.102 \\
Abdominal bleeding & 1 & 4 & 0 & 0.604 \\
Chyle leakage & 2 & 5 & 0 & 0.405 \\
Pleural effusion & 1 & 11 & 1 & 0.382 \\
Gastric stasis & 0 & 0 & 1 & 0.082 \\
Ileus & 1 & 8 & 2 & 0.794 \\
\hline
\end{tabular}

was significantly worse than that with normal $(P<0.001)$ or high BMI $(P=0.004)$. The overall survival of patients with normal and high BMI was comparable $(P=0.783)$.

The overall survival was also analyzed for patients after propensity score matching (Fig. 2). The overall survival of patients with low BMI was significantly worse than patients with normal $(P=0.001)$ or high BMI $(P=$ 0.031 ). However, the overall survival was comparable between patients with normal and high BMI $(P=0.731)$. Further, the overall survival of patients stratified by tumor stage were analyzed. For stage I and II patients, the overall survival was comparable among the three groups (both $P>0.05$ ). For stage III patients, the overall survival of patients with low BMI was significantly worse than that with normal $(P=0.003)$ or high BMI $(P=$ 0.025). The overall survival of patients with normal and high BMI was comparable $(P=0.954)$.

\section{Discussion}

BMI is a widely used parameter in clinical practice due to easy measurement. BMI is associated with a variety of cancer, including gastric cancer [15]. A meta-analysis has demonstrated that high BMI was associated with increased risk of gastric cardia cancer [16]. The association between BMI and clinical outcomes of gastric cancer has also been widely investigated, however, it was still under debate [10-13]. Thus, the present study aims to investigate the impact of BMI on the clinical outcomes of gastric cancer after radical gastrectomy. We found

Table 5 Univariate analysis of risk factors for prognosis of gastric cancer after matching

\begin{tabular}{llll}
\hline Prognostic factors & $\beta$ & Hazard ratio $(95 \% \mathrm{Cl})$ & $P$ value \\
\hline Gender & -0.127 & $0.881(0.643-1.206)$ & 0.428 \\
Age & 0.326 & $1.386(1.075-1.786)$ & 0.012 \\
BMI & -0.256 & $0.774(0.619-0.969)$ & 0.025 \\
Tumor location & 0.056 & $1.058(0.933-1.199)$ & 0.380 \\
Tumor size & 0.769 & $2.158(1.670-2.787)$ & $<0.001$ \\
Borrmann type & 0.357 & $1.429(1.260-1.621)$ & $<0.001$ \\
Pathological type & 0.467 & $1.596(1.289-1.975)$ & $<0.001$ \\
Type of gastrectomy & 0.432 & $0.649(0.522-0.808)$ & $<0.001$ \\
Tumor depth & 0.854 & $2.348(1.929-2.858)$ & $<0.001$ \\
Lymph node metastasis & 0.591 & $1.807(1.586-2.058)$ & $<0.001$ \\
Tumor stage & 1.239 & $3.451(2.575-4.623)$ & $<0.001$ \\
\hline
\end{tabular}


Table 6 Multivariate analysis of risk factors for prognosis of gastric cancer after matching

\begin{tabular}{llll}
\hline Prognostic factors & $\beta$ & Hazard ratio $(95 \% \mathrm{Cl})$ & $P$ value \\
\hline Age & 0.198 & $1.219(0.940-1.582)$ & 0.136 \\
BMI & 0.332 & $0.717(0.570-0.903)$ & 0.005 \\
Tumor size & 0.345 & $1.412(1.077-1.851)$ & 0.013 \\
Borrmann type & 0.080 & $1.083(0.943-1.244)$ & 0.259 \\
Pathological type & 0.120 & $1.128(0.900-1.414)$ & 0.297 \\
Type of gastrectomy & -0.065 & $0.937(0.743-1.181)$ & 0.582 \\
Tumor depth & 0.560 & $1.751(1.397-2.193)$ & $<0.001$ \\
Lymph node metastasis & 0.403 & $1.496(1.298-1.724)$ & $<0.001$ \\
\hline
\end{tabular}

that BMI was inversely associated with tumor stage. High BMI group was associated with increased blood loss and operation time, and deceased number of retrieved lymph nodes. Low BMI group was associated with decreased rate of postoperative fever and decreased survival of patients.

The association between BMI and tumor stage was inconsistent in previous reports. Kim et al. reported that low BMI was associated with more advanced tumor stage [4]. Chen et al. reported that low BMI was associated with increased rate of lymph node metastasis and advanced tumor stage, but not associated with tumor depth [11]. However, no association between BMI and tumor stage has also been reported [12, 17]. The inconsistent results may attribute to many reasons, such as inclusion and exclusion criteria, sample size, cut off value of BMI, race, etc. As gastrointestinal malignancy, gastric cancer always accompanied with severe weight loss and cachexia [18]. Thus, advanced gastric cancer may be more inclined to exist in patients with low BMI. In our present study, we also found that BMI was inversely associated with tumor depth, lymph node metastasis and tumor stage.

The impact of BMI on intraoperative conditions were also widely investigated. Patients with high BMI was reported to be associated with increased blood loss [19, 20], increased operation time $[17,21]$ and decreased number of retrieved lymph nodes $[10,22]$ in most of previous reports. However, no association between BMI and intraoperative conditions has also been reported [23, 24] occasionally. Based on clinical experiences, obesity was thought to be associated with thick abdominal wall and massive adipose tissue in the abdomen, which will increase the difficulty of surgical resection [17]. Thus, the blood loss was increased and operation time was prolonged [11]. Furthermore, lymph nodes located deep in adipose tissue around major vessels were always difficult to remove in high BMI patients [10]. In our present study, we also found that high BMI was also associated with increased blood loss, operation time and decreased number of retrieved lymph nodes. No difference was found between low and normal BMI patients. The results were consistent with most of the previous reports.

From the surgical point of view, high BMI patients was thought to be associated with increased postoperative complications due to the prolonged operation time and increased blood loss. This has been confirmed by most of the previous reports. Kulig et al. reported that
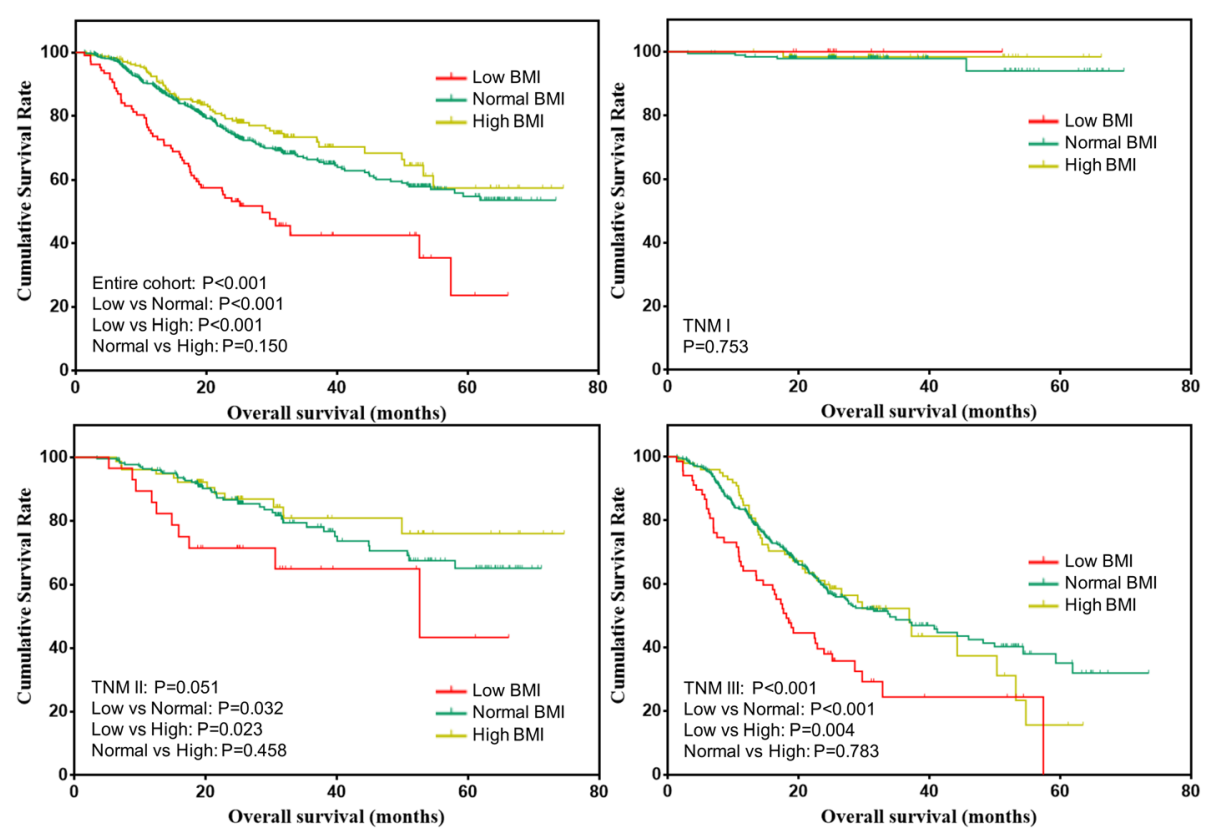

Fig. 1 Overall survival of gastric cancer patients stratified by BMI before matching 

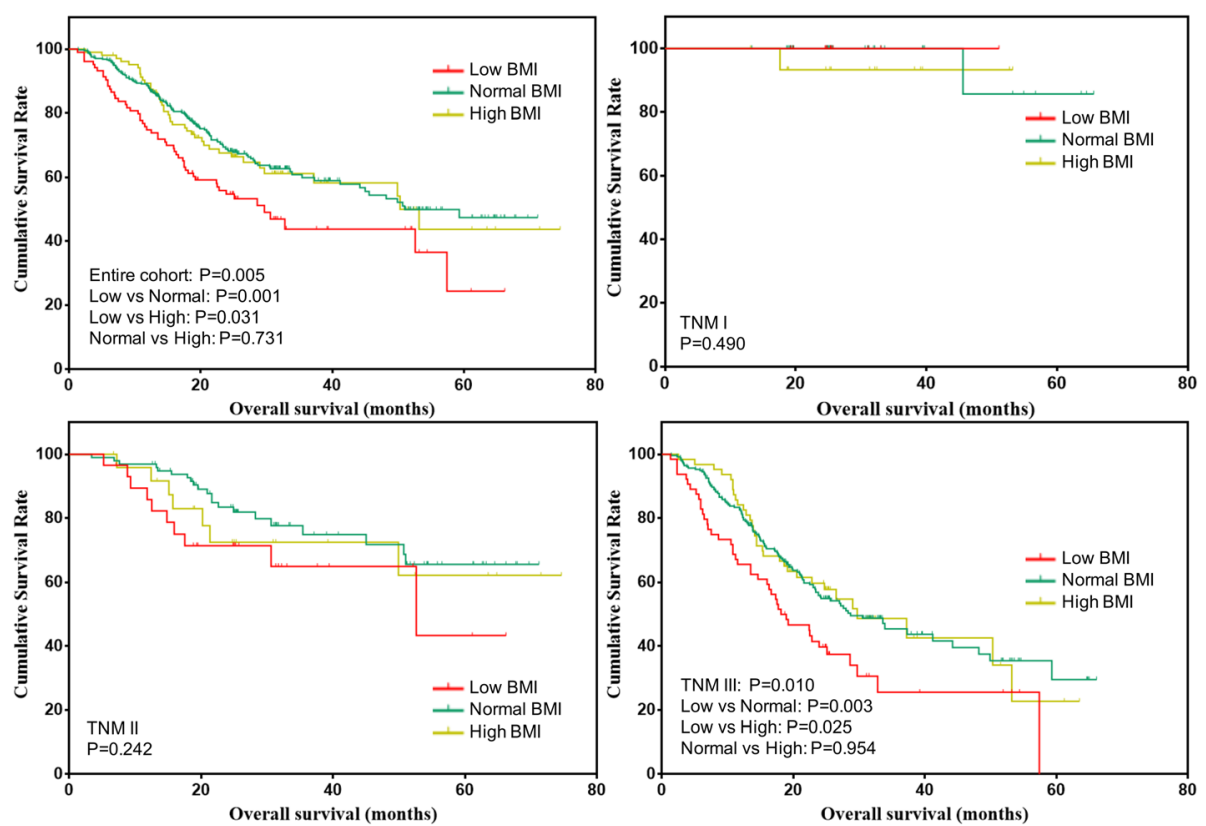

Fig. 2 Overall survival of gastric cancer patients stratified by BMI after matching

higher BMI was associated with higher rates of intraabdominal abscess and cardiopulmonary complications [22]. Kim et al. also reported that obese was associated with higher rate of intra-abdominal abscess, wound problems and overall complications [20]. Hirao et al. showed that overweight was an independent risk factor for surgical site infection [19]. This risk may attribute to greater wound size and decreased oxygen tension in relatively avascular adipose tissue in overweight patients [19]. In addition, high BMI was also reported to be associated with anastomotic leak [10]. Theoretically, massive abdominal adipose tissue would result in a thick mesentery and increased tension on an anastomosis, which may result in anastomotic leakage [10]. However, no association between BMI and postoperative complications was also reported [12, 17]. In our present study, we found that normal and high BMI group was associated with increased rate of postoperative fever. The inconsistence of the results may attribute to sample size, type of gastrectomy, surgical techniques and perioperative nursing and treatment.

It was well known that overweight and obesity was a risk factor of death in general population [25]. However, "obesity paradox" has been proposed recently, referring to better prognosis of mildly obese patients after surgery [11]. The association between BMI and prognosis of patients after radical gastrectomy has also been widely investigated. Chen et al. reported that BMI was inversely associated with the prognosis of patients [11]. Tokunaga et al. reported that overweight patients had better prognosis after gastrectomy [26]. However, also with relatively large sample size, no association was found between BMI and prognosis of gastric cancer [10, 22, 27]. In our present study, low BMI was associated with decreased prognosis of gastric cancer. However, the prognosis was comparable between patients with normal and high BMI. It was reported that gastrectomy may result in $5 \%-19 \%$ body weight loss [26]. Thus, overweight patients may achieve ideal body weight years after gastrectomy, which may result in better prognosis. It was reported that cancer patients with low BMI was always accompanied by low hemoglobin and albumin levels which may due to poor nutritional status and cachexia [11]. The malnutrition in turn will impair the anti-tumor immunity of patients [28]. In the subgroup analysis in our present study, only the prognosis of patients with stage III disease was significantly influenced by BMI, which indicated that patients with normal and high BMI might be more able to bear cancer related malnutrition and stress.

There were several limitations in our present study. First, it was a single center's experience with limited sample size, which may result in bias during analysis. Multi-center study with larger sample size was needed to confirm our results. Second, we only analyzed the impact of BMI at diagnosis on the clinical outcomes of patients. The impact of body weight loss before surgery on the clinical outcomes of patients were not analyzed. Third, as there were only twenty-three obese patients $\left(\mathrm{BMI} \geq 30 \mathrm{Kg} / \mathrm{m}^{2}\right)$ in our present study. We only divided patients into low, normal and high BMI groups. The impact of obesity on the clinical outcomes of gastric cancer was not independently analyzed. Fourth, it was reported that visceral fat area may be superior to BMI to predict 
the risk of gastrectomy. With regret, visceral fat area of patients was not evaluated in our present study.

\section{Conclusions}

BMI was inversely associated with tumor size, tumor depth, LNM and tumor stage. High BMI was associated with increased blood loss and operation time, and deceased number of retrieved lymph nodes. Low BMI was associated with decreased rate of postoperative fever and decreased survival of patients.

\section{Abbreviations}

BMI: body mass index; LNM: lymph node metastasis

\section{Acknowledgments}

Not applicable.

\section{Funding}

This study was supported in part by grants from the National Natural Scientific Foundation of China [NO. 31100643, 31570907, 81300301، 81572306, 81502403, XJZT12Z03].

\section{Availability of data and materials}

The datasets generated and/or analyzed during the current study are available from the corresponding author on reasonable request.

\section{Authors' contributions}

FF, ZG and GX was responsible for conception and design. LZ, XG, WF and WQ contributed to collection and assembly of data. Data analysis and interpretation were performed by GM and LX. ZH designed and supervised the study. All authors read and approved the final manuscript. All authors contributed to the writing of the manuscript and provided final approval of the manuscript. All authors have read and approved the final version of this manuscript.

\section{Authors' information}

Not further applicable.

\section{Ethics approval and consent to participate}

This study was approved by the Ethics Committee of Xijing Hospital, and written informed consent was obtained from the patients in our center.

\section{Consent for publication}

Not applicable.

\section{Competing interests}

The authors declare that they have no competing interests.

\section{Publisher's Note}

Springer Nature remains neutral with regard to jurisdictional claims in published maps and institutional affiliations.

\footnotetext{
Author details

'Division of Digestive Surgery, Xijing Hospital of Digestive Diseases, Fourth Military Medical University, 127 West Changle Road, Xi'an, Shaanxi 710032 , China. ${ }^{2}$ Department of General Surgery, No. 534 Hospital of PLA, West Lichun Road, Luoyang, Henan 471000, China. ${ }^{3}$ Department of General Surgery, No. 91 Hospital of PLA, 239 Gongye Road, Jiaozuo, Henan 454000, China.
}

Received: 2 August 2017 Accepted: 29 January 2018

Published online: 06 February 2018

\section{References}

1. Torre LA, Bray F, Siegel RL, Ferlay J, Lortet-Tieulent J, Jemal A. Global cancer statistics, 2012. CA Cancer J Clin. 2015;65(2):87-108.

2. Chen W, Zheng R, Baade PD, Zhang S, Zeng H, Bray F, Jemal A, Yu XQ, He J. Cancer statistics in China, 2015. CA Cancer J Clin. 2016;66(2):115-32.
3. Marano L, Polom K, Patriti A, Roviello G, Falco G, Stracqualursi A, De Luca R, Petrioli R, Martinotti M, Generali D, et al. Surgical management of advanced gastric cancer: an evolving issue. Eur J Surg Oncol. 2016;42(1):18-27.

4. Kim JM, Park JH, Jeong SH, Lee YJ, Ju YT, Jeong CY, Jung EJ, Hong SC, Choi SK, Ha WS. Relationship between low body mass index and morbidity after gastrectomy for gastric cancer. Ann Surg Treat Res. 2016;90(4):207-12.

5. Liedman B, Andersson H, Berglund B, Bosaeus I, Hugosson I, Olbe L, Lundell L. Food intake after gastrectomy for gastric carcinoma: the role of a gastric reservoir. Br J Surg. 1996;83(8):1138-43.

6. Alipour S, Kennecke HF, Woods R, Lim HJ, Speers C, Brown CJ, Gill S, Renouf DJ, Cheung WY. Body mass index and body surface area and their associations with outcomes in stage II and III colon cancer. J Gastrointest Cancer. 2013; 44(2):203-10.

7. Blom RL, Lagarde SM, Klinkenbijl JH, Busch OR, van Berge Henegouwen MI. A high body mass index in esophageal cancer patients does not influence postoperative outcome or long-term survival. Ann Surg Oncol. 2012;19(3):766-71.

8. Bao PP, Cai H, Peng P, Gu K, Su Y, Shu XO, Zheng Y. Body mass index and weight change in relation to triple-negative breast cancer survival. Cancer Causes Control. 2016:27(2):229-36.

9. Dahlberg SE, Schiller JH, Bonomi PB, Sandler AB, Brahmer JR, Ramalingam SS, Johnson DH. Body mass index and its association with clinical outcomes for advanced non-small-cell lung cancer patients enrolled on eastern cooperative oncology group clinical trials. J Thorac Oncol. 2013;8(9):1121-7.

10. Bickenbach KA, Denton B, Gonen M, Brennan MF, Coit DG, Strong VE. Impact of obesity on perioperative complications and long-term survival of patients with gastric cancer. Ann Surg Oncol. 2013;20(3):780-7.

11. Chen HN, Chen XZ, Zhang WH, Yang K, Chen XL, Zhang B, Chen ZX, Chen JP, Zhou ZG, Hu JK. The impact of body mass index on the surgical outcomes of patients with gastric cancer: a 10-year, single-institution cohort study. Medicine (Baltimore). 2015;94(42):e1769.

12. Ejaz A, Spolverato G, Kim Y, Poultsides GA, Fields RC, Bloomston M, Cho CS, Votanopoulos K, Maithel SK, Pawlik TM. Impact of body mass index on perioperative outcomes and survival after resection for gastric cancer. J Surg Res. 2015;195(1):74-82.

13. Voglino C, Di Mare G, Ferrara F, De Franco L, Roviello F, Marrelli D. Clinical and oncological value of preoperative BMI in gastric cancer patients: a single center experience. Gastroenterol Res Pract. 2015;2015:810134

14. Japanese gastric cancer treatment guidelines 2010 (ver. 3). Gastric Cancer 2011;14(2): 113-23.

15. Yang P, Zhou Y, Chen B, Wan HW, Jia GQ, Bai HL, Wu XT. Overweight, obesity and gastric cancer risk: results from a meta-analysis of cohort studies. Eur 」 Cancer. 2009;45(16):2867-73.

16. Chen Y, Liu L, Wang X, Wang J, Yan Z, Cheng J, Gong G, Li G. Body mass index and risk of gastric cancer: a meta-analysis of a population with more than ten million from 24 prospective studies. Cancer Epidemiol Biomark Prev. 2013;22(8):1395-408.

17. Wada T, Kunisaki C, Ono HA, Makino H, Akiyama H, Endo I. Implications of BMI for the prognosis of gastric cancer among the Japanese population. Dig Surg. 2015;32(6):480-6.

18. Liu BZ, Tao L, Chen YZ, Li XZ, Dong YL, Ma YJ, Li SG, Li F, Zhang WJ. Preoperative body mass index, blood albumin and triglycerides predict survival for patients with gastric cancer. PLoS One. 2016;11(6):e0157401.

19. Hirao M, Tsujinaka T, Imamura H, Kurokawa Y, Inoue K, Kimura Y, Shimokawa T, Furukawa H. Osaka gastrointestinal cancer chemotherapy study group (OGSG). Overweight is a risk factor for surgical site infection following distal gastrectomy for gastric cancer. Gastric Cancer. 2013;16(2):239-44.

20. Kim MG, Yook JH, Kim KC, Kim TH, Kim HS, Kim BS, Kim BS. Influence of obesity on early surgical outcomes of laparoscopic-assisted gastrectomy in gastric cancer. Surg Laparosc Endosc Percutan Tech. 2011;21(3):151-4.

21. Struecker B, Biebl M, Dadras M, Chopra S, Denecke C, Spenke J, Heilmann AC, Bahra M, Sauer IM, Pratschke J, et al. The impact of obesity on outcomes following resection for gastric cancer. Dig Surg. 2017;34(2):133-41.

22. Kulig J, Sierzega M, Kolodziejczyk P, Dadan J, Drews M, Fraczek M, Jeziorski A, Krawczyk M, Starzynska T, Wallner G, et al. Implications of overweight in gastric cancer: a multicenter study in a western patient population. Eur J Surg Oncol. 2010;36(10):969-76

23. Wang Z, Zhang X, Liang J, Hu J, Zeng W, Zhou Z. Short-term outcomes for laparoscopy-assisted distal gastrectomy for body mass index $\geq 30$ patients with gastric cancer. J Surg Res. 2015;195(1):83-8.

24. Wong J, Rahman S, Saeed N, Lin HY, Almhanna K, Shridhar R, Hoffe S, Meredith KL. Effect of body mass index in patients undergoing resection for 
gastric cancer: a single center US experience. J Gastrointest Surg. 2014;18(3): 505-11.

25. Adams KF, Schatzkin A, Harris TB, Kipnis V, Mouw T, Ballard-Barbash R, Hollenbeck A, Leitzmann MF. Overweight, obesity, and mortality in a large prospective cohort of persons 50 to 71 years old. N Engl J Med. 2006;355(8): 763-78.

26. Tokunaga M, Hiki N, Fukunaga T, Ohyama S, Yamaguchi T, Nakajima T. Better 5-year survival rate following curative gastrectomy in overweight patients. Ann Surg Oncol. 2009;16(12):3245-51.

27. Lin YS, Huang KH, Lan YT, Fang WL, Chen JH, Lo SS, Hsieh MC, Li AF, Chiou $\mathrm{SH}, \mathrm{Wu} \mathrm{CW}$. Impact of body mass index on postoperative outcome of advanced gastric cancer after curative surgery. J Gastrointest Surg. 2013; 17(8):1382-91.

28. Fox CJ, Hammerman PS, Thompson CB. Fuel feeds function: energy metabolism and the T-cell response. Nat Rev Immunol. 2005;5(11):844-52.

Submit your next manuscript to BioMed Central and we will help you at every step:

- We accept pre-submission inquiries

- Our selector tool helps you to find the most relevant journal

- We provide round the clock customer support

- Convenient online submission

- Thorough peer review

- Inclusion in PubMed and all major indexing services

- Maximum visibility for your research

Submit your manuscript at www.biomedcentral.com/submit
Biomed Central 